\title{
Bolsa Família: projeto social ou marketing político?
}

\author{
Paulo Gabriel Martins de Moura \\ Universidade Luterana do Brasil (ULBRA)
}

Bolsa Família: projeto social ou marketing político?

Resumo: Esse ensaio, à luz da análise política, critica o Programa Bolsa Família, implementado pelo governo Lula, a partir da metodologia de ongoing analysis conjuntural, originada na ciência política norte-americana. Busca estabelecer paralelo dessas análises com as críticas de especialistas ao Bolsa Família, veiculadas na imprensa, que sugerem a ausência de um referencial conceitual, amparado no conhecimento acumulado na área (ou sua não-aplicação prática), a nortear as políticas sociais do governo Lula. Baseando-se em fontes secundárias sobre dados oficiais e em depoimentos de especialistas, a análise identifica uma aparente 'esquizofrenia' nos referenciais 'filosóficos' que norteiam as políticas sociais do governo, sugerindo que a solução escolhida foi uma resposta conjuntural a uma demanda de marketing governamental, e não orientada por uma deliberada política pública de governo pré-concebida como tal que, se existiu, não transparece nas ações governamentais aplicadas.

Palavras-chave: governo Lula, políticas sociais públicas, Bolsa Família, Fome Zero, marketing político.

\section{Family Grant: Social Policy or Political Marketing?}

Abstract: This essay, a political analysis, criticizes the Family Grant Program, implemented by the Lula government of 2003-2005. It is based on the ongoing analysis methodology originated in U.S. political science. It seeks to establish a parallel of these analyses with criticisms of the Family Grant program presented in the media and made by specialists. They focus on the absence of a conceptual reference for the program (or its practical non-application), supported by accumulated knowledge in the field, that would guide the social policies of the Lula government. Based on secondary sources about official data and on statements from specialists, the analysis identifies an apparent 'schizophrenia' in the 'philosophical' references that orient the government's social policies, suggesting that the solution chosen was a situational response to a demand for government marketing and not oriented to a deliberate public policy preconceived as such, which, if it exists, is not evident in the government actions.

Key words: Lula government, public social policies, Family Grant, Zero Hunger, political marketing. 
O presente ensaio tem a modesta pretensão de ser uma primeira análise crítica do autor sobre o Programa Bolsa Família, implementado pelo governo do presidente Luiz Inácio Lula da Silva na segunda metade de seu primeiro mandato (2003-2006). Os pontos de vista aqui expressos estão ancorados em dados divulgados em matérias do jornal Folha de São Paulo, num artigo de Augusto de Franco (FRANCO, 2003, p. 86-106) intitulado Três Gerações de Políticas Sociais, e, do ponto de vista conjuntural, em análises do próprio autor, ao longo do mandato do atual presidente da República.

Segundo Augusto de Franco, “[...] as políticas de intervenção centralizada do Estado, as políticas públicas de oferta governamental descentralizada e as políticas públicas de parceria entre Estado e sociedade para o investimento no desenvolvimento social, representam três gerações diferentes de políticas sociais". Para esse autor, na década de 80 do século 20 , foram as políticas de intervenção centralizada do Estado na área social que predominaram, praticadas pela ação de técnicos da burocracia do setor público. Nesse período, predominava um padrão de "atuação clientelista e paternalista de atores políticos populistas ou de setores oligárquicos conservadores" que controlavam o poder público. No entanto, afirma Franco, "as sementes desse tipo de política foram plantadas nos anos anteriores, em grande parte na década de 1970", sob a vigência do regime militar.

Implícita à lógica que orientava a aplicação dessas políticas sociais, estava a concepção de que apenas a ação do Estado era suficiente para suprir as carências da sociedade por esse tipo de política pública; de que os benefícios repassados pelo Estado à população carente são concessões e/ou resultado de práticas de "intermediação político-partidária, eleitoral ou institucional"; de que os serviços embutidos nessas políticas públicas "não são encarados propriamente como direitos"; e, finalmente, de que a gestão governamental dessas políticas não é concebida como tendo natureza pública, não sendo, portanto, transparente. Ou seja, a forma como essas políticas sociais eram aplicadas incorporava "graus insuficientes de accountability" e não incorporava "outros atores na sua elaboração, na sua execução, no seu monitoramento, na sua avaliação, no seu controle ou na sua fiscalização".

Para Franco, na década subseqüente "predominaram as políticas públicas universais, baseadas na oferta estatal", sintetizadas no conceito de que essas políticas sociais são um "direito do cidadão" e um “dever do Estado". Não obstante, as concepções e as práticas que teriam possibilitado a difusão desse tipo de política foram experimentadas na década anterior e foram incorporadas ao arcabouço legal da Constituição de 1988.

O autor destaca que a segunda geração de políticas sociais públicas caracteriza-se pela "oferta go- vernamental descentralizada", organizada e implementada a partir da concepção de que o Estado não seria mais suficiente para sua implementação, mas ainda cumpriria "um (quase) exclusivo papel protagônico (desde que consiga se publicizar, razão pela qual as políticas públicas são encaradas, apenas ou principalmente, como políticas governamentais)". Para seu desenvolvimento dever-se-ia "perseguir os objetivos da despartidarização e da despersonalização", em função da necessidade de evitar-se a "intermediação político-partidária, eleitoral ou mesmo institucional, na oferta dos recursos públicos". Dever-se-ia, ainda eliminar gradativamente as práticas do clientelismo e do assistencialismo; priorizando-se "a preocupação com a eficiência, a eficácia e a efetividade dos programas e das ações de governo, com seu monitoramento e avaliação e com a sua fiscalização ou controle por parte da sociedade". E, finalmente, as ações deveriam ser direcionadas para públicos-alvos específicos, tais como os envolvidos em trabalho infantil, portadores de deficiências, crianças, gestantes e nutrizes em situação de risco, dentre outros.

Os programas universais, sob essa orientação, segundo Franco, eram orientados, em grande parte, pela concepção de sua aplicação de forma centralizada, com sua execução sendo pensada a partir da "oferta massiva e indiferenciada". Sob essa orientação, afirma Franco, "os bilhões destinados para programas de previdência social, saúde e saneamento, educação, qualificação para o trabalho, combate à pobreza e distribuição de terra e de renda", comporiam uma "rede de proteção social", concebida como "sucedâneo ou substitutivo, no caso do Brasil, do inatingido (e inatingível) welfare state".

Augusto de Franco afirma, ainda, que a terceira geração das políticas sociais deveria se orientar por outras concepções que ainda se observam de modo insipiente no Brasil na entrada do século 21. Segundo o autor, o conceito-chave que deveria orientar a aplicação das políticas sociais públicas deveria basear-se na "máxima giddesiana" sintetizada na idéia "nenhum direito sem responsabilidade". Sob a orientação desse conceito, "as políticas sociais de terceira geração são políticas multi e intersetoriais de desenvolvimento social, de investimento em ativos (nas potencialidades já existentes em setores e localidades) e não apenas de gasto estatal para satisfazer necessidades setoriais".

A superação das concepções, que orientaram as políticas sociais predominantes na década de 90 do século passado, deveria, segundo Franco, basear-se nas idéias de que, embora o Estado tenha um papel insubstituível na implementação das políticas sociais públicas, sua intervenção não seria suficiente para a implementação de projetos nessa área, "devendo-se, portanto, lançar mão de parcerias e buscar constelar 
sinergias entre todos os setores (o Estado, o mercado e a sociedade civil) para promover o desenvolvimento". Além disso, Franco entende que políticas públicas não são, necessariamente, sinônimos de "políticas governamentais", isto é, não caberia ao Estado "deter o monopólio do público". O autor, portanto, estabelece uma clara distinção entre a esfera governamental de ação social e "uma esfera pública não-estatal" que estaria em expansão na sociedade atual e que seria constituída por entes e processos da sociedade civil de caráter público, voltados, cada vez mais, a promoção do desenvolvimento".

A promoção do o desenvolvimento social, sob esse ponto de vista, não constituiria "uma tarefa lateral e separável das outras tarefas do Estado como indutor do desenvolvimento", já que, para ele, "todo desenvolvimento é desenvolvimento social". Dessa forma, "induzir o desenvolvimento" implicaria em "investir em capacidades permanentes de pessoas e comunidades (ou seja, basicamente, investir em capital humano e em capital social) para que possam afirmar uma nova identidade no mundo ao ensaiar seu próprio caminho de superação de problemas e de satisfação de necessidades, tornando dinâmicas suas potencialidades para antecipar o futuro que almejam".

Augusto de Franco foi membro da direção nacional do Partido dos Trabalhadores (PT) e, no governo do ex-presidente Fernando Henrique Cardoso (19952002), integrou o Programa Comunidade Solidária, através do qual aquele governo implementava suas políticas sociais públicas. Não obstante ter integrado os quadros do PT e ser formulador de uma análise crítica sofisticada e abrangente das políticas sociais públicas aplicadas no Brasil, não se vêem, ao longo da trajetória histórica desse partido, cuja retórica é a da prioridade social, a preocupação teórica e prática com a implementação de políticas públicas voltadas para a redução das desigualdades sociais.

Tendo nascido e crescido aplicando a retórica de defesa dos pobres, que terminou influenciando decisivamente a eleição de seu líder máximo Luis Inácio Lula da Silva à Presidência da República, o PT gerou na sociedade uma enorme expectativa de que, no poder, finalmente desenvolveria políticas públicas capazes de satisfazer essa demanda social. Eleito em 2002, Lula anunciou o Programa Fome Zero como carro-chefe da suposta política social de seu governo. No entanto, depois de passados sete meses de mandato, prazo em que o presidente eleito já teria tido tempo de mostrar a que viera nessa área, a percepção que o governo Lula deixava transparecer sobre o Fome Zero, não parecia confirmar as expectativas geradas na sociedade com relação às políticas sociais de seu programa de governo.

Em novembro de 2003, já se podiam constatar integrantes do governo reagindo defensivamente às críticas ao Fome Zero. As pesquisas de opinião publicadas revelavam que o Fome Zero, apesar de sua inconsistência como programa social, ainda usufruía de uma cotação positiva junto à opinião pública. Ao lado do carisma do presidente, essa marca é o que sustentava boa parte dos bons índices de aprovação que o governo ostentava na época.

Segundo pesquisa Datafolha, divulgada em 02 de novembro de 2003 (DATAFOLHA, 2006), o percentual dos entrevistados que consideram a fome o principal problema do país é de $12 \%$. Já o percentual dos que acreditam que esse é o setor no qual Lula está se saindo melhor é de $28 \%$. Foram citadas como áreas de melhor desempenho, além do combate à fome e à miséria, entre outras, a educação (7\%), a saúde, a economia de modo geral $(6 \%$, cada) e a área social $(5 \%)$. As expectativas de que o governo Lula teria um desempenho Ótimo ou Bom na área social caíra de $78 \%$ para $53 \%$ após dez meses da posse do presidente, mas ainda eram significativamente altas, conforme essa pesquisa.

A maioria da opinião pública parecia comprar a imagem do Fome Zero pela idéia generosa subjacente à marca, apesar da inconsistência do conceito de política social nele embutido, se considerados os pontos de vista de Augusto de Franco antes explicitados.

A sustentação da popularidade dessa marca, junto à opinião pública, sugeria um razoável grau de desinformação da população sobre a realidade prática das políticas públicas do governo Lula para o setor social.

Em entrevistas à imprensa concedidas por Frei Beto, à época assessor especial do presidente Lula, assim como a publicidade de rádio do Fome Zero levada ao ar na rádio CBN no mesmo período (suponho que em âmbito nacional e também em outros veículos), já sugeria a constatação de problemas de 
percepção negativa junto à segmentos líderes da opinião pública, sobre esse 'projeto social' do governo.

O foco das entrevistas do assessor especial do presidente e dos spots publicitários do governo concentrava-se em negar o caráter paternalista do Fome Zero, além de remeter para o futuro a ampliação do número de beneficiados pelo programa.

Não faria sentido adotar essa retórica oficial numa campanha publicitária veiculada nacionalmente sem antes testá-la em baterias de pesquisas quantitativas e qualitativas que os estrategistas de marketing político da Presidência da República costumam aplicar para orientar as estratégias de comunicação do governo com a sociedade. Logo, se o governo sentiu necessidade de afirmar que o Fome Zero não tem caráter paternalista é porque constatou que setores estratégicos da opinião pública assim o percebem.

Segundo as modernas teorias da opinião pública e da comunicação, os prognósticos de eventuais mudanças de comportamento político da população baseiamse na interpretação de pesquisas, na avaliação qualitativa dos conteúdos que, formadores de opinião, veiculam nos meios de comunicação e na análise do comportamento dos agentes políticos, que se referenciam na percepção das reações da sociedade às ações de governo, nem sempre bem captadas pelas pesquisas superficiais publicadas. A observação atenta da leitura, que esses indicadores apontavam à época, sugere que os estrategistas de marketing do governo poderiam estar tentando, ao veicular uma campanha publicitária nessa linha, antecipar-se para evitar a falência da marca Fome Zero. Nesse sentido, inclusive, convém relembrar a sintomática demissão do outro importante ex-assessor presidencial para essa área, o empresário Oded Grajew.

Ao afirmar que, apenas no futuro, o Fome Zero ampliaria o número de famílias atendidas pelos programas sociais do governo, o que a publicidade oficial fazia era reconhecer implicitamente que até aquele momento a principal iniciativa social do governo Lula mostrava-se incapaz de apresentar resultados palpáveis.

Quais poderiam ser as origens do suposto erro do governo na implementação de suas políticas sociais?

$\mathrm{O}$ erro talvez tenha origem num problema de natureza ideológica, relacionado às teorias socialistas de transformação social, dominantes no imaginário dos quadros do PT, não obstante a falência do paradigma marxista. Nem Marx nem os marxistas se dedicaram a teorizar sobre a arte de governar sobre o funcionamento da sociedade e do Estado após a chegada dos comunistas ao poder.

A preocupação das esquerdas com a democracia e a gestão pública está ausente em todas as vertentes do pensamento socialista, pelo menos até o fim da União Soviética, não obstante as dissidências que se abriram nas esquerdas em relação ao regime implantado na Rússia após 1917. Essas preocupações teóricas por parte de pensadores de esquerda, portanto, são recentíssimas, incipientes e erráticas.

Na mentalidade predominante entre as esquerdas antes da queda do Muro de Berlim, vigorava uma concepção segundo a qual os problemas da sociedade tenderiam a desaparecer com a estatização dos meios de produção; o planejamento central da economia e a decorrente distribuição da riqueza a ser promovida pelo Estado Operário após a implantação do socialismo. Conseqüentemente, sequer faria sentido pensar no regime socialista sob a vigência da democracia, e com isso, na necessidade da formulação de políticas públicas tal como às de combate à fome, à inflação, ao desemprego, aos problemas da saúde, da educação e da segurança pública (MOURA, 2001).

Com o fim da URSS e a falência do paradigma marxista, impôs-se às esquerdas o desafio de gerir e reformar o capitalismo, dentro das regras da democracia. Ocorre que, pelas razões antes explicitadas, ao chegarem ao poder, pela via de vitórias eleitorais sob a vigência de regimes democráticos, as esquerdas se viram despreparadas, teórica e praticamente, para enfrentar o desafio da gestão do Estado sob a vigência do capitalismo.

Desprovidas do modelo teórico marxista clássico como norte de suas ações políticas e tendo que enfrentar o desafio de governar o capitalismo, as esquerdas terminam fazendo-o sem um projeto de governo; sem referência em conceitos sólidos; sem uma estratégia e sem projetos setoriais específicos, coerentes com diretrizes gerais que sequer existem.

A segunda possível explicação para a percepção negativa do Fome Zero, junto ao público sondado, parece ter origem e relação com o erro anteriormente referido, e é muito comumente praticado, por políticos que, sem projeto de governo e/ou sem planejamento estratégico para sua implementação, tendem a submeter suas ações a critérios exclusivamente publicitários. Trata-se, se essa linha de análise estiver correta, da supervalorização da forma em detrimento do conteúdo. Ou seja, a idéia do projeto Fome Zero parece ter surgido mais como marca, isto é, como uma idéia de marketing, do que propriamente amparada numa concepção teórica e estratégica que deveria orientar políticas públicas consistentes.

Uma das conseqüências decorrentes dessa concepção é o rápido desencontro da 'idéia genial' com seus limites, na medida em que não corresponde à realidade prática; não produz resultados em termos de estatísticas socioeconômicas capazes de atestar sua eficácia na redução das desigualdades sociais. Daí até a produção de percepção pública negativa, dada a sua inconsistência tal como sugerida pelas duas aferições antes referidas, é um passo.

Um terceiro fator que parece corroborar essa situação foi a mudança implementada pelo governo na concepção e na condução das suas políticas sociais 
públicas no período imediatamente subseqüente. O risco que o presidente Lula correria se a deixasse proliferar, sem tentar reverter essa percepção negativa crescente de suas políticas sociais junto a setores formadores de opinião da sociedade, seria o de frustrar as expectativas geradas, não apenas por sua retórica eleitoral de 2002, mas pelos 25 anos anteriores em que o Partido dos Trabalhadores se constituiu e cresceu, vendendo a idéia de que a sua chegada ao poder corresponderia à aplicação de políticas de governo voltadas para a redução das desigualdades sociais.

Nesse sentido, substituir a ministra Benedita da Silva (Promoção Social) e o ministro José Graziano (Segurança Alimentar), nos cargos que ocupavam nessa área estratégica para a imagem pública do presidente e de seu governo, foi o primeiro passo das mudanças que o governo implementou na área social dali para frente.

Constatada a imagem crescentemente negativa do Programa Fome Zero como ícone do marketing social do governo, que, como dissemos, seria um dos carros-chefe da estratégia de reeleição do presidente Lula, impôs-se a necessidade de o governo executar uma operação política e de marketing visando 'reposicionar essa marca perante o mercado'.

Observe-se que as pesquisas revelavam que, como marca percebida pela opinião pública, o Fome Zero ainda cumpria a função de preservar a imagem do governo Lula como um governo voltado para o social. Assim, a iniciativa adotada pelo governo, num primeiro momento, foi no sentido de tentar reposicionar a própria marca Fome Zero, visando conferir-lhe algum conteúdo. Aparentemente, essa tentativa revelou-se infrutífera; a guerra da comunicação já estava perdida nesse front, conforme sugerem as mudanças implementadas no segundo momento.

A partir daí, então, entra em campo o discreto ministro Patrus Ananias (Desenvolvimento Social e Combate à Fome), que passa a coordenar, distante dos holofotes da mídia, a operação política e administrativa de substituição do Programa Fome Zero pelo Bolsa Família. Trabalhando em silêncio, ao melhor estilo dos políticos mineiros, Patrus Ananias unificou todos os programas sociais do governo anterior, ampliou o número de famílias atendidas para cerca de 11,1 milhão (conforme a propaganda eleitoral de Lula/2006) e, o que é mais importante, atribuiu-lhes uma única marca (Bolsa Família) com ampla visibilidade nacional. Mais importante do que isso, em dois anos de distribuição de dinheiro à população pobre, o governo conseguiu melhorar as estatísticas sociais do país.

Segundo declaração da secretária nacional de renda de cidadania do Ministério do Desenvolvimento Social, Rosani Cunha, em matéria publicada em 28/05/2006 pelo jornal Folha de São Paulo (FOLHAONLINE, 2006b), o Bolsa Família já estaria caminhando no sentido de priorizar o acesso dos be- neficiados a outros programas do governo: "Desde o ano passado, há um trabalho, por exemplo, de integração do Bolsa Família com o Brasil Alfabetizado. O programa já funciona hoje como eixo integrador de outros. Esse movimento já está em curso e está muito maduro, mas tem que se estender por mais programas e se capilarizar". O mesmo esforço já estaria em andamento junto aos Ministérios da Educação, do Trabalho e de Minas e Energia, em diferentes projetos.

O Bolsa Família, dessa forma, adquiriu também uma dimensão simbólica, imprescindível ao marketing reeleitoral do presidente Lula, visto ter permitido difundir a idéia de que esse é um governo que faz pelos pobres mais do que qualquer outro que o antecedeu na história do país. Como símbolo, portanto, o Bolsa Família conferiu ao governo uma marca social com a qual os estrategistas de marketing do candidato Lula à reeleição puderam reconquistar o apoio da parcela da classe média que antes votava no PT na expectativa de solução dos problemas sociais do país.

Os resultados eleitorais colhidos pelo PT nas eleições municipais de 2004 e o resultado do referendo das armas de 2005 atestavam um divórcio histórico entre o PT e a classe média, especialmente nas regiões mais desenvolvidas do país. A classe média abandonou o PT, tudo indica, depois de sentir no bolso as conseqüências da política econômica que o então ministro Palocci (Fazenda, de 2003 a março de 2006) implementou na primeira fase do governo Lula, mas também pela desilusão e decepção com os sucessivos escândalos de corrupção que se sucederam após o primeiro de todos eles, envolvendo Waldomiro Diniz, ex-assessor do ex-ministro José Dirceu (Casa Civil).

Estudo do economista Waldir Quadros da Unicamp, publicado na Folha de São Paulo em 12/ $11 / 2004$, revela que mais de 2,5 milhões de pessoas, pertencentes a famílias com renda superior a $\mathrm{R} \$$ 1.000 , perderam a condição de classe média em 2003. Cerca de 57 milhões de brasileiros enquadravam-se em famílias com esse perfil de renda no ano de 2002. Em 2003, revela a pesquisa, eles eram 54,4 milhões para uma população total de 173 milhões. Dessa forma, a classe média, que representava $33 \%$ da população total em 2002, passou a representar $31 \% \mathrm{em}$ 2003. Segundo os dados aferidos, 928 mil pessoas deixaram a classe média alta, e outras 680 mil que se enquadravam na 'classe média média' em 2002 não mais poderiam ser classificadas nessa condição no ano passado. $\mathrm{Na}$ chamada classe média baixa o estrago não foi menor. Esse segmento perdeu $980 \mathrm{mil}$ membros, na maioria dos casos, ocorrendo transferência para as classes inferiores (FOLHAONLINE, 2006c).

Segundo o economista, nem todos os 4,8 milhões de integrantes da classe média são pessoas que perderam renda ou emprego em 2003, já que parte do 
fenômeno se explica pelo crescimento populacional. Mas, diz ele, "essa piora é o retrato da política econômica de 2003", e não a uma suposta "herança maldita" do governo FHC, muito embora a tendência já fosse percebida anteriormente. A queda, diz o economista, ocorreu de forma acelerada, mas a recuperação é lenta.

Reconstituir as relações do governo Lula junto a essa parcela do eleitorado, portanto, tornou-se um imperativo estratégico para que o candidato Lula pudesse vislumbrar perspectivas de vencer a eleição de 2006. Tudo indica que essa parcela do eleitorado poderia vir a votar em Lula outra vez, apesar dos escândalos de corrupção que se abateram sobre o governo, se fosse compensada pelas perdas de 2003 e se pudesse acreditar na imagem projetada pelo marketing social do governo, que vendia a versão de que Lula tem resultados concretos a mostrar na diminuição das desigualdades sociais do país.

As pesquisas que projetavam a possível vitória de Lula na reta final da eleição de 2006 sugerem que essa operação política e de marketing do governo pode ter dado os resultados esperados, não obstante às inúmeras críticas de especialistas aos limites e contradições do Bolsa Família como modelo de projeto de política pública governamental. Além do marketing do Bolsa Família, o governo Lula editou medidas concretas beneficiando a classe média no ano eleitoral.

A propaganda do candidato Lula nas eleições de 2006 afirmava que o Bolsa Família atingiria 11,1 milhões de domicílios até o fim do ano. Os dados oficiais revelavam que em 2004, eram 6,7 milhões os atendidos. Não obstante o reconhecimento dos benefícios sociais dessas políticas públicas, ONGs que desenvolvem projetos dessa natureza denunciaram irregularidades no cadastramento de beneficiários desses programas oficiais. Matérias publicadas por diversos órgãos de imprensa, após a substituição do Fome Zero pelo Bolsa Família, denunciam que inúmeros prefeitos, através de vereadores, distribuíam cotas do dinheiro do programa com a finalidade de garantir apoio eleitoral. Especialistas propõem, para evitar esse tipo de vulnerabilidade, a unificação do cadastramento dos programas municipais, estatais e federais para facilitar a fiscalização.

Além disso, segundo dados da Pesquisa Nacional por Amostra de Domicílios, em 2004, (PNAD, 2006), dos 18 milhões de domicílios com algum nível de insegurança alimentar, apenas 5,3 milhões (29\% do total) eram beneficiários dos programas sociais de transferência de renda. Em 2004, antes da posse de Lula, portanto, 12,5 milhões domicílios ainda eram vulneráveis à fome e não recebiam repasses do governo, sendo que as estatísticas oficiais indicam que 8 milhões tinham algum morador beneficiado por programas governamentais de transferência de renda. No entanto, dentre os beneficiados por projetos de transferências de renda, os dados mostravam que a maioria (66\%) tinha ao menos um morador que relatou algum nível de insegurança alimentar.

Os dados indicam, ainda, que em 34\% dos domicílios que recebiam recursos de transferência de renda não havia preocupação de provimento de alimentos para uma dieta saudável, devido às restrições de renda. Apesar dos programas oficiais, dentre os domicílios atendidos por programas sociais 14,9\% estavam em situação de insegurança alimentar grave, na qual moradores relataram que chegaram a passar fome ao menos uma vez nos três meses anteriores à pesquisa realizada em outubro de 2004.

Para Lena Lavinas, do Instituto de Economia da UFRJ, os dados relevam a "enorme exclusão das políticas sociais" e comprovam ainda, que os programas são "mal desenhados e inadequados", havendo um erro de focalização gravíssimo” (LAVINAS, 2006).

Dentre as distorções de foco dos investimentos sociais do governo, dados oficiais revelam, também, que 3 milhões de funcionários públicos federais aposentados recebem anualmente $\mathrm{R} \$ 76$ bilhões, ao passo que o Bolsa Família transferiu, em 2005, R \$ 5,5 bilhões em recursos a 8,7 milhões de famílias, o que atingia, na época, cerca de 32 milhões de pessoas. Ou seja, os 8,7 milhões de famílias beneficiadas receberam 7,4\% do valor destinado aos $3 \mathrm{mi}-$ lhões de aposentados federais.

Dados oficiais atestam que a Previdência Social brasileira gasta cerca de três vezes com aposentadorias públicas e privadas o que o Estado investe em educação, área cujas estatísticas oficiais apontam resultados catastróficos. Para fins comparativos observe-se que para um montante de cerca $\mathrm{R} \$ 5,5$ bilhões repassados pelo governo ao Bolsa Família em 2005, somente no primeiro trimestre deste mesmo ano, os gastos do Governo Federal com pessoal e despesas da máquina aumentaram em R \$ 6,9 bilhões (FOLHAONLINE, 2006d).

Segundo o Instituto Brasileiro de Planejamento Tributário (IBPT, 2006) 37\% do PIB é o montante de impostos que o Estado brasileiro arrecada para financiar todo o setor público e suas políticas. Em valores absolutos, trata-se de R\$ 755 bilhões. Parcela 
significativa desse dinheiro financia as aposentadorias de funcionários públicos e os juros da dívida pública, constituindo-se em gastos sem retorno para o crescimento econômico.

Pesquisadores identificaram, ainda, já sob a vigência do governo Lula, a existência de cerca de 150 programas sociais que, em tese, ajudariam os seus beneficiários a viver sem ajuda oficial. Na opinião de Lavinas, ao contrário do que o governo fez ao agrupar e centralizar os programas integrados sob a marca Bolsa Família, projetos desse tipo seriam descoordenados e desfocados, o que induziria os beneficiários da ajuda governamental em dinheiro a tornarem-se dependentes perenes da "esmola oficial" (FOLHAONLINE, 2006e).

A julgar pelas críticas dos especialistas, o governo estaria agindo como se seus projetos de transferência de renda fossem um fim e não um meio transitório para a emancipação social dos beneficiados, menosprezando, dessa forma, a importância das estratégias de desenvolvimento local, de geração de renda e de ampliação e melhoria da oferta de serviços públicos de saúde e educação como medidas que não deveriam ser substituídas por iniciativas de caráter meramente assistencialista.

Lavinas afirma que o "Bolsa Família é só uma forma de organizar a fila, na qual os mais pobres nunca são os primeiros por desinformação ou porque simplesmente o recurso destinado ao município acaba. Os programas de transferência de renda têm de contemplar todos que precisam, que pela pesquisa são 72 milhões de pessoas" (FOLHAONLINE, 2006e).

Pesquisadores reunidos no dia 26/05/2006 no seminário Pobreza, Desigualdade e Desenvolvimento, promovido por Folha de São Paulo, Centro Brasileiro de Análise e Planejamento (Cebrap) e Institute of Development Studies, da Universidade de Sussex, para discutir a desigualdade social no Brasil, concordaram que "as políticas sociais implementadas no país desde ao menos o governo Fernando Henrique Cardoso têm melhorado sua qualidade e abrangência. Porém, dizem, os resultados são "contraditórios", (CARIELLO, 2006).

Segundo o pesquisador Marcus Melo, da Universidade Federal de Pernambuco, e Eduardo Marques, pesquisador do Cebrap, "uma das marcas da ampliação do acesso a serviços e políticas públicas para os pobres do Brasil nos últimos anos é a ausência de ‘intermediação’ por lideranças políticas, religiosas ou de outro tipo, que seria um indicador de que a prática do clientelismo teria diminuído nesse período". De acordo com Marques, uma recente pesquisa do Cebrap indicou uma "significativa redução" nas desigualdades no acesso a serviços públicos em São Paulo, afirmando ter identificado uma tendência nacional à redução da pobreza nas grandes cidades"(CARIELLO, 2006).
Mesmo assim, os pesquisadores apontam resultados "contraditórios". Para Marques, a persistência de altos níveis de segregação espacial dos pobres nas grandes cidades, fator que contribui para a reprodução da desigualdade, e o baixo crescimento da economia no período, tiveram reflexos negativos sobre o nível de emprego, gerando conseqüências, do ponto de vista das estatísticas socioeconômicas, que caminham em sentido oposto ao dos resultados colhidos pelas políticas públicas oficiais de combate à pobreza"(CARIELLO, 2006).

Zander Navarro, da Universidade Federal do Rio Grande do Sul, defendeu a necessidade de rápida redução da pobreza afirmando que "se não há crescimento, não vamos a lugar nenhum”, ao passo que Marcus Melo classificou os resultados das políticas sociais como "pífios", afirmando que "há benefícios que distribuem renda (como a aposentadoria rural e o Bolsa Família) e outros que contribuem para manter a desigualdade. O pesquisador sustentou seus pontos de vista no argumento de que os gastos com aposentadorias de servidores públicos e o INSS e o SUS (Sistema Único de Saúde) são "concentradores". No último caso, isso se deve ao fato de que o SUS paga por serviços prestados na rede hospitalar, concentrada em $80 \%$ da rede, nas regiões Sul e Sudeste do país (CARIELLO, 2006).

Já a professora do Departamento de Planejamento Alimentar e Nutrição da Unicamp, Elisabete Salay, critica o projeto Bolsa Família argumentando que o foco "levar comida à população" deveria ser reformulado para um sentido mais amplo e/ou de maior pertinência social, como campanhas para a educação", por exemplo. Para Salay, "os programas de transferência podem reverter o quadro de insegurança alimentar, desde que bem focados na população mais necessitada e implementados em conjunto com outras ações" (FOLHA DE SÃO PAULO, 2006).

As críticas de pesquisadores da área aqui identificadas apontam inúmeras contradições e limites das políticas sociais do governo Lula, que, não obstante, parecem colher boa receptividade junto à opinião pública após a substituição da marca Fome Zero pelo Programa Bolsa Família.

Um contraste entre a análise conceitual proposta por Augusto de Franco e sintetizada na abertura do presente ensaio, com as críticas dos especialistas aqui arroladas, sugere a ausência (ou, se houve, a nãoaplicação) de um referencial conceitual unívoco e atualizado do ponto de vista do conhecimento acumulado na área, como elemento norteador das diretrizes governamentais para suas políticas sociais. Nossa análise, ainda que superficial, sugere haver uma aparente confusão e uma certa 'esquizofrenia' nos referenciais 'filosóficos' que norteiam as múltiplas experiências oficiais do governo Lula em ter- 
mos de políticas sociais. Tudo indica que a solução escolhida para o governo foi uma resposta conjuntural à uma demanda de marketing governamental, portanto, mais do que orientada por uma deliberada política pública de governo pré-concebida como tal.

\section{Referências}

CARIELLO, R. Gastos sociais têm efeito contraditório, afirmam analistas. Folha Online, em 27.06.2006. Disponível em <www1.folha.uol.com.br/folha/brasil/ult96u78995. shtml>. Acesso em: out. 2006.

DATAFOLHA. Instituto de Pesquisas. Opinião pública. Avaliação de governo. Disponível em $<$ http://datafolha. folha.uol.com.br/po/aval_pres_21122003a.shtml>.Acesso em: out. 2006

FOLHA DE SÃO PAULO. Campanha 'Natal sem Fome' acaba após 13 anos, em 21.05.2006. Disponível em $<$ www1.folha.uol.com.br/fsp/brasil/fc2105200633.htm>. Acesso em: out. 2006.

FOLHAONLINE. Brasil. Disponível em <www1.folha. uol.com.br/folha/brasil/>. Acesso em: out. 2006a.

Arquivos da Folha, Rosani Cunha, em 28.05.2006. Disponível em <www1.uol.com.br/cgi-bin/bibliot/arquivo. cgi?html=fsp2006 $>$. Acesso em: out. 2006 b.

. Arquivos da Folha, Waldir Quadros, em 12.11.2004. Disponível em <www1.uol.com.br/cgi-bin/ bibliot/arquivo.cgi?html=fsp2004 $>$. Acesso em: out. 2006c.

Arquivos da Folha, de 30.04.2006. Disponível em <www1.uol.com.br/cgi-bin/bibliot/arquivo.cgi?html $=$ fsp2006 $>$. Acesso em: out. 2006d.

. Arquivos da Folha, Lena Lavinas em 21.05.2006. Disponível em <www1.uol.com.br/cgi-bin/bibliot/ arquivo.cgi?html=fsp2004 $>$. Acesso em: out. 2006e.

FRANCO, A. de. Três gerações de políticas sociais. Separata da Revista Aminoácidos, 5. Brasília: AED, 2003.

IBPT-Instituto Brasileiro de Planejamento Tributário. Serviços. Carga tributária potencial brasileira 2006. Disponível em <www.ibpt.com.br/estudos/estudos. 1st.php>. Acesso em: out. 2006.

LAVINAS. L. O nó é outro. O Globo Online, Arquivo Premium, 4 abr. 2006. Disponível em $<$ http://arquivoglobo. globo.com/ie_index.htm>. Acesso em: out. 2006.

MOURA, P. G. M. de. PT: comunismo ou social-democracia? Porto Alegre: Ed. Soles, 2001.
PNAD-Pesquisa Nacional por Amostra de Domicílio 2004. Disponível em <www.ibge.gov.br/home/estatistica/ populacao/trabalhoerendimento/pnad2004>. Acesso em: out. 2006.

\section{Paulo Gabriel Martins de Moura}

Doutor em Comunicação Social pela Pontifícia Univ. Católica do Rio Grande do Sul (PUCRS)

Professor de Ciência Política na Universidade Luterana do Brasil (ULBRA)

Rua Miguel Tostes, 101

Bairro São Luiz

Canoas - Rio Grande do Sul

CEP: $92420-280$ 